\title{
Airway function at one year: association with premorbid airway function, wheezing, and maternal smoking
}

\author{
C Dezateux, J Stocks, A M Wade, I Dundas, M E Fletcher
}

\begin{abstract}
Background-Impaired growth and development of the respiratory system during fetal and early postnatal life may have important implications for lung development and later lung health. The aim of this study was to examine the association of diminished premorbid airway function, prior wheezing, and maternal smoking with airway function at 1 year of age.

Methods-Respiratory function was measured at the end of the first year in $\mathbf{1 0 0}$ of 108 healthy term infants $(93 \%)$ in whom similar measurements had been undertaken prior to any respiratory illness at 8 weeks. Physician diagnosed wheezing episodes were identified retrospectively from medical records.
\end{abstract}

Results-At 1 year specific airway conductance during end expiration (sGawEE; $/ \mathrm{s} / \mathrm{kPa}$ ) was significantly diminished in those infants with prior wheezing $(95 \% \mathrm{CI}$ wheeze/no wheeze -0.76 to -0.14 ), mothers who smoked (95\% CI smoke/no smoke -0.81 to -0.27 ), a family history of asthma (95\% CI family history/no family history -0.62 to 0.00 ), or diminished premorbid sGaweE $(95 \%$ CI -0.13 to $-0.43 / \mathrm{s} / \mathrm{kPa}$ per unit reduction sGaweE at 8 weeks). In a multivariate model only maternal smoking and diminished premorbid sGawEE were independently associated with diminished sGaweE at 1 year.

Conclusions-Diminished airway function at the end of the first year appears to be mediated by impaired airway development during early life as well as by exposure to maternal smoking. These findings are consistent with the hypothesis that, at a population level, diminished premorbid airway function provides the link between wheezing lower respiratory illness and diminished airway function at 1 year. Maternal smoking remains an important and avoidable cause of impaired airway development and function in infancy.

(Thorax 2001;56:680-686)

Keywords: infant; lung function tests; wheezing; lower respiratory illness; fetal development; smoking

Diminished respiratory function in the first few months of life precedes and is predictive of wheezing in early childhood, ${ }^{1-3}$ an association which may be mediated by genetic and environmental factors. ${ }^{4}$ It has been suggested that suboptimal development of the respiratory system during fetal life or early childhood may influence airway function adversely throughout life. ${ }^{56}$ Diminished airway function has been reported in young children with prior early wheezing illness. ${ }^{78}$ However, the interplay between premorbid respiratory function, prior wheezing lower respiratory illness, and environmental and genetic influences and their respective contributions to respiratory function in later infancy remains unclear, reflecting a lack of population based studies with sequential measurements of infant lung function.

Although the respiratory system grows and develops most rapidly during fetal and early postnatal life, ${ }^{9}$ there are few longitudinal lung function data available for the early years. Postnatal lung growth may be diminished among those exposed to wheezing illnesses or adverse environmental factors during the first year, and this may be more marked among those with prior impairment of respiratory function. Alternatively, the level of respiratory function in later infancy may be independent of prior wheezing or of preceding level of respiratory function.

The aim of this prospective community based study was to examine the association between respiratory function at 1 year of age, prior wheezing, and premorbid respiratory function. It was hypothesised that airway function at 1 year would be diminished in infants with prior wheezing, but that this association would be mediated by diminished premorbid airway function measured shortly after birth, before the development of upper or lower respiratory symptoms.

\section{Methods}

STUDY POPULATION

Eligible infants were identified from consecutive births to women registered with two health centres in inner London. Healthy white term infants ( $>35$ weeks) without major congenital abnormalities or neonatal or prior respiratory illness were eligible. Families were not approached if social or medical reasons precluded contact, and those planning to leave the area over the next year were ineligible. Parents were contacted by letter and written informed parental consent obtained following at least one prearranged home visit by the research nurse. This study was approved by the ethics committee of the Hospitals for Sick Children, London. 
RESPIRATORY FUNCTION

Respiratory function was measured on two occasions in each infant: before the development of any respiratory symptoms when aged 1-3 months, and at approximately 1 year of age when infants were symptom free and when at least 2 weeks had elapsed since any upper and lower respiratory symptoms. Measurements were made following sedation with triclofos sodium elixir $(75-100 \mathrm{mg} / \mathrm{kg})$ during behaviourally determined quiet sleep as described previously. ${ }^{10-12}$ On each test occasion body weight was measured to the nearest $100 \mathrm{~g}$ and crown-heel length to the nearest $0.1 \mathrm{~cm} .{ }^{10}$

Airway function was assessed from plethysmographic measurements of airway resistance (Raw) from which conductance (Gaw), the reciprocal of Raw, was calculated. ${ }^{11}$ Since there is rapid growth of the airways during the first year of life, resistance will be higher (and conductance lower) in smaller, younger infants. By dividing conductance by functional residual capacity (FRCpleth) to obtain specific conductance (sGaw), account can be taken of these growth related changes.

Measurements of sGaw made during end expiration (sGawEE) were chosen as the principal measure of airway function in this study. These provide a measure of effective airway calibre corrected for lung size and will be reduced if airway calibre is diminished and/or lung volume increased in relation to body size. Similar measurements made during initial inspiration (sGawII) are reported but were not used as outcomes in regression analyses. Respiratory function parameters were calculated according to previously established criteria. ${ }^{112}$ Respiratory system compliance was measured using the multiple occlusion technique $^{10}$ to allow differences in airway function to be interpreted with respect to any underlying differences in elastic recoil. Specific compliance (sCrs, compliance/FRCpleth) was also calculated to determine whether changes in elastic recoil during the first year reflected increases in FRCpleth.

Although of uncertain relevance as measures of airway function, ${ }^{13}$ tidal breathing parameters including respiratory rate $(\mathrm{RR})$ and the time to peak tidal expiratory flow as a proportion of total expiratory time (tPTEF:tE) were also calculated. This allowed comparison with previously published work in which tPTEF:tE has been reported to be diminished in young infants who subsequently wheeze in early childhood ${ }^{1}$ and in those with a family history of asthma and parental smoking. ${ }^{14-16}$

WHEEZING AND OTHER FACTORS

Obstetric, medical, social, and demographic details were obtained at recruitment when mothers were asked to report their smoking during pregnancy and whether any first degree relative of the child had ever been diagnosed with asthma. Gestation-specific birth weight standard deviation scores were calculated for each infant. ${ }^{17}$ Maternal smoking postnatally as well as exposure to tobacco smoke from other household members was assessed from the parental report at the second test when a specimen of urine was collected from each infant and frozen at $-20^{\circ} \mathrm{C}$ within two hours of voiding. Urinary cotinine levels were assayed by gas liquid chromatography ${ }^{18}$ and expressed as ng cotinine/mg creatinine. Following the second respiratory function test, physician diagnosed episodes of wheezing in the first year of life were identified retrospectively from the child's practice medical record by a researcher blinded to the results of the respiratory function tests.

STATISTICAL METHODS

SGawEE and TPTEF:tE at 1 year were compared by sex, prior wheezing status, family history of asthma, postnatal exposure to maternal smoking, and sGaweE at 8 weeks (SPSS for Windows version 7.5.1). The association between sGaweE at 1 year and sex, prior wheezing, maternal smoking, family history of asthma, or sGawEE measured shortly after birth was examined using linear regression. Similar analyses were carried out for tPTEF:tE at 1 year. This study was established to examine the association of five potential independent variables with airway function. Sample size calculations suggested that, should these variables together account for $16 \%$ or more of the variability in sGawEe at 1 year, a sample of 85 infants would allow this to be detected with $80 \%$ power at the $5 \%$ significance level, or with $90 \%$ power if they accounted for $21 \%$ or more of the variability. ${ }^{19}$ Should any single variable account for more than $9 \%$ of the variability in sGaweE at 1 year, this sample would allow this to be detected with $80 \%$ power, or with $90 \%$ power for more than $14 \%$ of the variability.

\section{Results}

Over a 5 year period the parents of 118 of 300 eligible infants $(39 \%)$ born in the study practices and successfully contacted consented to their child having respiratory function tests. Following recruitment, 10 of these children developed respiratory symptoms before respiratory tests could be arranged and were hence excluded from respiratory function testing. Parents of a further 148 infants declined testing but agreed to participate in a parallel morbidity study so that background data were available for $266(89 \%)$ of all eligible and contacted infants. As reported previously, ${ }^{2}$ infants whose parents agreed to respiratory function tests were similar with respect to birth weight, gestational age, sex distribution, maternal age and educational level, and prevalence of family history of asthma to those for whom only background data were available.

Respiratory function was measured on the first test occasion and before development of any upper or lower respiratory symptoms in 108 children. During their first year, five of these 108 infants were lost to follow up, while the parents of a further three declined the 1 year test. Thus, respiratory function was measured on a second occasion in 100 children (93\% of those enrolled; 51 boys) who form the basis of this report. Paired measurements of 
Table 1 Infant characteristics by test occasion

\begin{tabular}{|c|c|c|c|}
\hline & First test ${ }^{\star}$ & Second test ${ }^{\star}$ & $\begin{array}{l}\text { Mean }(95 \% \text { CI) + within-subject difference } \\
\text { between second and first test }\end{array}$ \\
\hline Postnatal age (weeks) & $7.8(1.4)$ & $55.9(4.9)$ & 48.2 (47.2 to 49.2$)$ \\
\hline Body weight (kg) & $4.9(0.7)$ & $9.9(1.2)$ & $5.0(4.8$ to 5.2$)$ \\
\hline Crown-heel length $(\mathrm{cm})$ & $57.6(2.5)$ & $77.6(2.7)$ & $20.0(19.5$ to 20.5$)$ \\
\hline FRCpleth (ml) & $112(26)$ & $249(42)$ & $136(129$ to 144$) \ddagger$ \\
\hline RawiI (kPa/l.s) & $4.11(2.02)$ & $2.33(1.30)$ & $-1.85(-2.30$ to -1.39$) \rrbracket$ \\
\hline RaweE (kPa/l.s) & $4.57(2.46)$ & $2.46(1.35)$ & $-2.24(-2.73$ to -1.76$) \int$ \\
\hline sGawII (/s/kPa) & $2.64(1.02)$ & $2.09(0.71)$ & $-0.51(-0.76$ to -0.27$) \Phi$ \\
\hline sGawEe (/s/kPa) & $2.41(0.93)$ & $1.99(0.71)$ & $-0.36(-0.57$ to -0.16$) \S$ \\
\hline Crs $(\mathrm{ml} / \mathrm{kPa})$ & $65.6(10.7)$ & $145.5(20.9)$ & 80.4 (76.9 to 83.9$)$ \\
\hline $\mathrm{sCrs}(/ \mathrm{kPa})$ & $0.61(0.12)$ & $0.60(0.10)$ & $-0.01(-0.04 \text { to } 0.02)^{\star \star}$ \\
\hline tPTEF:tE & $0.324(0.074)$ & $0.299(0.079)$ & $-0.024(-0.040$ to -0.008$)$ \\
\hline Respiratory rate (bpm) & $46(9)$ & $30(4)$ & $-16(-17$ to -14$)$ \\
\hline
\end{tabular}

FRCpleth = functional residual capacity determined plethysmographically; Raw = airway resistance measured at initial inspiration (RawII) or end expiration (RawEE); sGaw = specific conductance measured at initial inspiration (sGawII) or end expiration (sGawEE); sCrs = specific respiratory compliance; tPTEF:tE = time to peak tidal expiratory flow as a proportion of total expiratory time.

$\star$ Data summarised as mean (SD).

$+95 \% \mathrm{CI}=95 \%$ confidence interval of difference in means for 100 infants unless otherwise stated.

$\neq \mathrm{n}=99 ; \mathrm{\Upsilon n}=86 ; \uparrow \mathrm{n}=92 ;{ }^{\star \star} \mathrm{n}=91$.

tPTEF:tE at 8 weeks and 1 year of age were successfully obtained in all 100 infants. Measurements of sGaweE were successful at 1 year in 98 infants, including $85(99 \%)$ of the 86 with similar measurements at 8 weeks of age. ${ }^{2}$ Details of respiratory function on each test occasion for all infants and within-subject changes between occasions for infants with complete data on both occasions are summarised in table 1 .

The second test was performed at a mean (range) age of 56 weeks (48-78), an average 48 weeks after the first test (95\% CI 47 to 49 weeks). During this interval body weight increased on average by $5.0 \mathrm{~kg}$ and crown-heel length by $20.0 \mathrm{~cm}$, while FRCpleth doubled and sGaweE, sGawir, and tPTEF:tE declined to a small but significant extent (table 1). Respiratory rate declined from 46 to $30 \mathrm{bpm}$ whereas sCrs remained constant, reflecting the parallel increase in lung volume and compliance during the first year of life.

During the interval between the first and second respiratory function test, 27 of 98 children $(28 \%)$ whose primary medical care record was successfully located experienced at least one episode of physician diagnosed wheezing. Of those with wheezing, 11 had more than one episode (two episodes in five children, three episodes in two, four episodes in three, and five episodes in one). Four of the 27 children required at least one hospital admission for management of their wheezing episode and a further two were seen in hospital during an

Table 2 Background characteristics at 1 year by prior wheezing status ${ }^{a}$

\begin{tabular}{|c|c|c|c|}
\hline & $\begin{array}{l}\text { Wheeze } \\
(n=27)\end{array}$ & $\begin{array}{l}\text { No wheeze } \\
(n=71)\end{array}$ & $\begin{array}{l}95 \% \text { CI of difference } \\
\text { between wheeze and } \\
\text { no wheeze }\end{array}$ \\
\hline Boys (n) & $63 \%(17)$ & $45 \%(32)$ & -4 to 40 \\
\hline First degree relative with asthma (n) & $52 \%(14)$ & $18 \%(13)$ & 13 to $53 \$$ \\
\hline Postnatal maternal smoking (n) & $63 \%(17)$ & $30 \%(21)$ & 11 to $55 \dagger$ \\
\hline Birth weight $(\mathrm{g})$ & $3189(557)$ & $3508(456)$ & -536 to $-101 \dagger$ \\
\hline Gestation (weeks) & $39.4(1.7)$ & $40.2(1.4)$ & -1.4 to $-0.1^{\star}$ \\
\hline Gestation-specific birthweight SD score ${ }^{17}$ & $-0.44(0.87)$ & $0.00(1.00)$ & -0.87 to $0.00^{\star}$ \\
\hline Birth weight centile $^{17}$ & $35.5(25.1)$ & $49.4(28.4)$ & -26.3 to $-1.6^{\star}$ \\
\hline Urinary cotinine:creatinine (ng & $\begin{array}{l}120.3 \\
(56.5-306.3)\end{array}$ & $\begin{array}{l}46.0 \\
(16.2-107.3)\end{array}$ & 1.5 to $4.5 \S$ \\
\hline
\end{tabular}

${ }^{\mathrm{a} D a t a}$ shown as mean (SD) for continuous and \% (n) for categorical variables; information on prior wheeze missing in two infants.

${ }^{b}$ Confidence intervals of difference in group means or percentages.

Urinary cotinine:creatinine ratios shown as geometric means (interquartile ranges) and their ratio ( $95 \%$ CI) with:without prior wheezing.

${ }^{\star} \mathrm{p} \leqslant 0.05 ;+\mathrm{p} \leqslant 0.01 ; \S \mathrm{p} \leqslant 0.001$ (two sided $t$ test for independent samples). acute episode, but not admitted, while 21 were managed by their general practitioner. Nine of the 27 were diagnosed clinically with acute bronchiolitis and 18 were treated on at least one occasion with either oral or nebulised salbutamol.

Infants with prior wheezing were more likely to have mothers who smoked, to have a family history of asthma, to weigh significantly less at birth, to be born at a slightly earlier gestation, and to be of lower birth weight for gestational age than those without such symptoms (table 2 ). While there was a slight excess of boys among those with wheezing, this difference was not statistically significant $(\mathrm{p}=0.06)$.

Respiratory function at 1 year of age was compared in those with and without prior wheezing, including 83 infants with complete data on wheezing and sGawEE for both test occasions, and 97 infants with complete data on wheezing and TPTEF:tE on both test occasions (table 3 ). At the time of the second respiratory function test, infants with prior wheezing were on average 2 weeks older but of similar body weight and crown-heel length to those with no wheezing. This reflected the fact that respiratory function tests sometimes had to be postponed until infants were free of respiratory tract symptoms. Among those with prior wheezing, RawEe at 1 year was significantly higher than in those without prior wheezing, but values of FRCpleth were similar. sGawEE was thus significantly lower among those with prior wheezing. A similar pattern was observed for RawII and sGawII. Although mean tPTEF:tE tended to be lower among those with prior wheezing, this was not statistically significant (table $3 ; \mathrm{p}=0.314$ ). $\mathrm{sCrs}$ and respiratory rate were also similar between the two groups.

FRCpleth and Crs were significantly higher in boys, reflecting their heavier body weight at testing (95\% CI of difference between boys and girls: 0.3 to $1.1 \mathrm{~kg} ; \mathrm{p}=0.002$ ). Thus, weight adjusted values for FRCpleth and Crs were not statistically different (data not shown). Boys and girls did not otherwise differ in respiratory function $(95 \% \mathrm{CI}$ of difference between boys and girls: sGaweE -0.23 to $0.34 / \mathrm{s} / \mathrm{kPa}$; tPTEF:tE -0.045 to 0.17 ).

A positive family history of asthma was reported in 28 children, and in 17 the mother 
Table 3 Respiratory function at 1 year by prior wheezing status

\begin{tabular}{llll}
\hline & Wheeze $(n=27)$ & $\begin{array}{l}\text { No wheeze } \\
(n=71)\end{array}$ & $\begin{array}{l}\text { 95\% CI of difference } \\
\text { between wheeze and no } \\
\text { wheeze }\end{array}$ \\
\hline Age (weeks) & $57.5(5.8)$ & $55.2(4.3)$ & 0.1 to $4.4^{\star}$ \\
Body weight $(\mathrm{kg})$ & $9.9(1.3)$ & $9.9(1.1)$ & -0.5 to 0.5 \\
Crown-heel length (cm) & $77.3(3.1)$ & $77.7(2.5)$ & -1.6 to 0.8 \\
FRCpleth $(\mathrm{ml})$ & $246(43)$ & $249(43)$ & -22 to 16 \\
RawiI $(\mathrm{kPa} / \mathrm{l} . \mathrm{s})$ & $2.75(1.34)$ & $2.18(1.27)$ & -0.03 to 1.15 \\
RaweE $(\mathrm{kPa} / \mathrm{l} . \mathrm{s})$ & $2.92(1.43)$ & $2.30(1.30)$ & 0.01 to $1.23^{\star}$ \\
sGawiI $(/ \mathrm{s} / \mathrm{kPa})$ & $1.80(0.66)$ & $2.19(0.69)$ & -0.70 to $-0.08^{\star}$ \\
sGawEE $(/ \mathrm{s} / \mathrm{kPa})$ & $1.66(0.53)$ & $2.11(0.73)$ & -0.76 to $-0.14 \dagger$ \\
sCrs $(/ \mathrm{kPa})$ & $0.59(0.07)$ & $0.60(0.11)$ & -0.06 to 0.03 \\
tPTEF:tE & $0.287(0.058)$ & $0.305(0.086)$ & -0.054 to 0.017 \\
Respiratory rate $(\mathrm{bpm})$ & $30(4)$ & $30(4)$ & -2 to 2 \\
\hline Abbreviations & &
\end{tabular}

Abbreviations as in footnote to table 1 .

${ }^{\star} \mathrm{p} \leqslant 0.05 ; \mathrm{tp} \leqslant 0.01$ (two sided $t$ test for independent samples).

Table 4 Respiratory function at 1 year by maternal smoking postnatally

\begin{tabular}{|c|c|c|c|}
\hline & $\begin{array}{l}\text { Mother smoker } \\
(n=38)\end{array}$ & $\begin{array}{l}\text { Mother non-smoker } \\
(n=62)\end{array}$ & $\begin{array}{l}95 \% \text { CI of difference } \\
\text { between smoker and } \\
\text { non-smoker }\end{array}$ \\
\hline Age (weeks) & $56.0(5.6)$ & $55.9(4.4)$ & -1.9 to 2.1 \\
\hline Body weight $(\mathrm{kg})$ & $9.8(1.3)$ & $10.0(1.1)$ & -0.6 to 0.3 \\
\hline Crown-heel length $(\mathrm{cm})$ & $77.2(2.6)$ & $77.9(2.7)$ & -1.8 to 0.4 \\
\hline $\begin{array}{l}\text { Urinary cotinine:creatinine } \\
(\mathrm{ng}: \mathrm{mg})^{\mathrm{a}}\end{array}$ & $\begin{array}{l}157.8 \\
(92.3-300.5)\end{array}$ & $\begin{array}{l}30.0 \\
(13.5-55.4)\end{array}$ & 3.6 to $7.7 \S$ \\
\hline FRCpleth (ml) & $243(44)$ & $251(41)$ & -26 to 9 \\
\hline RawII (kPa/l.s) & $2.76(1.42)$ & $2.06(1.14)$ & 0.16 to $0.25^{\star}$ \\
\hline RaweE $(\mathrm{kPa} / 1 . \mathrm{s})$ & $3.03(1.62)$ & $2.10(1.00)$ & 0.40 to 1.45 t \\
\hline sGawII $(/ \mathrm{s} / \mathrm{kPa})$ & $1.81(0.63)$ & $2.27(0.70)$ & -0.73 to -0.18 t \\
\hline sGaweE $(/ \mathrm{s} / \mathrm{kPa})$ & $1.66(0.60)$ & $2.20(0.69)$ & -0.81 to $-0.27 \S$ \\
\hline $\mathrm{sCrs}(\mathrm{kPa})$ & $0.58(0.09)$ & $0.61(0.10)$ & -0.07 to 0.01 \\
\hline tPTEF:tE & $0.297(0.084)$ & $0.300(0.076)$ & -0.036 to 0.029 \\
\hline Respiratory rate (bpm) & $29(3)$ & $30(4)$ & -2 to 1 \\
\hline
\end{tabular}

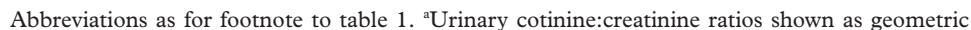
means (interquartile ranges) and their ratio (95\% CI) with:without exposure to maternal smoking. Other values are mean (SD). ${ }^{\star} \mathrm{p} \leqslant 0.05 ; \mathrm{tp} \leqslant 0.01 ; \S \mathrm{p} \leqslant 0.001$ (two sided $t$ test for independent samples).

was the affected family member. sGaweE was significantly lower in those with a positive family history than in those without (mean (SD): $1.77(0.63) / \mathrm{s} / \mathrm{kPa} v 2.09(0.72) / \mathrm{s} / \mathrm{kPa} ; 95 \% \mathrm{CI}$ of difference -0.62 to $-0.003 ; \mathrm{p}<0.05)$ which, in turn, reflects increased expiratory airway resistance among those with a family history (95\% CI of difference 0.00 to $1.19 \mathrm{kPa} / \mathrm{l} . \mathrm{s}$; $\mathrm{p}=0.05)$. Infants with wheezing were more likely to have a first degree relative with asthma (table 2).

Four of the 41 mothers who reported smoking during pregnancy ceased smoking once their child was born, while one mother who had not smoked when pregnant started smoking postnatally. Thus, the mothers of 38 children reported smoking since their child was born. Geometric mean urinary cotinine levels were $157.8 \mathrm{ng} / \mathrm{mg}$ creatinine in the infants whose mothers smoked postnatally and $30.0 \mathrm{ng} / \mathrm{mg}$ creatinine in those whose mothers did not smoke ( $95 \%$ CI of ratio smoke exposed:not smoke exposed 3.6 to $7.7 ; \mathrm{p}<0.001$ ). Infants who developed wheezing were twice as likely to have mothers who smoked postnatally (table 2). Infants of smoking mothers were of similar gestation but significantly lighter at birth ( $95 \%$ CI of difference -580 to $-200 \mathrm{~g}$; $\mathrm{p}<0.001$ ), resulting in significantly lower birth weight standard deviation scores $(95 \%$ CI of difference -0.96 to $-0.19 ; \mathrm{p}<0.01)$. However, at the time of the second lung function tests there were no significant differences in postnatal age, body weight, or crown-heel length

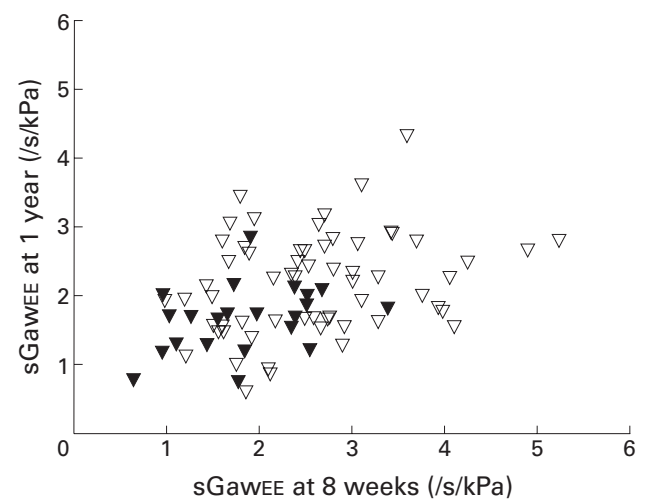

Figure 1 End expiratory specific airway conductance $(/ \mathrm{s} / \mathrm{kPa}$ ) measured at 8 weeks and 1 year according to prior wheezing status. Solid triangles $=$ infants with prior wheeze; open triangles $=$ infants without prior wheeze.

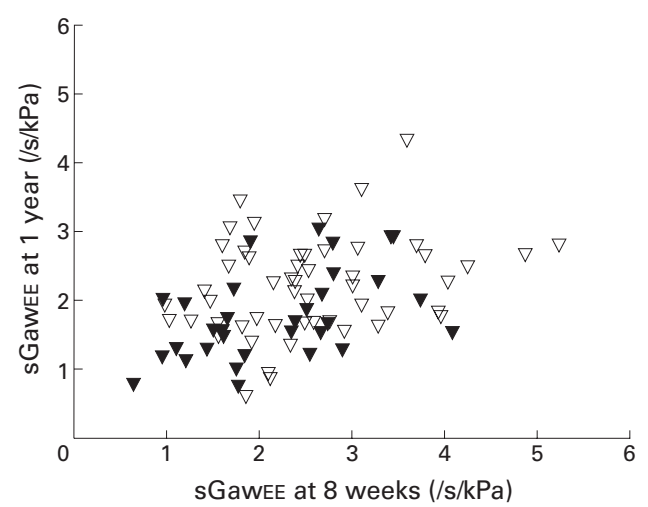

Figure 2 End expiratory specific airway conductance ( $/ \mathrm{s} / \mathrm{kPa}$ ) measured at 8 weeks and 1 year according to prior exposure to maternal smoking. Solid triangles $=$ infants whose mother smoked; open triangles = infants whose mother did not smoke.

(table 4). Both Rawil and RaweE were significantly raised and sGawII and sGawEe were significantly diminished in those infants whose mothers smoked postnatally, although FRCpleth, tPTEF:tE, and sCrs were similar.

sGawEE at 8 weeks of age and 1 year were significantly correlated (fig 1; Spearman's two tailed correlation coefficient $0.374 ; \mathrm{p}<0.01$ ), as were tPTEF:tE at 8 weeks and 1 year (Spearman's two tailed correlation coefficient 0.423 ; $\mathrm{p}<0.01)$. The association between sGawEe at 8 weeks of age and at 1 year is shown according to prior wheezing status in fig 1 , and according to maternal smoking status in fig 2 . In univariate analyses, sGawEE at 1 year was significantly and negatively associated with prior wheezing, being diminished on average by $0.45 / \mathrm{s} / \mathrm{kPa}$ in those with prior wheezing $(95 \% \mathrm{CI}-0.76$ to $-0.14 ; p=0.005$; table 5 ). It was also significantly and negatively associated with a family history of asthma and maternal smoking postnatally. sGawee was significantly lower at 1 year in those with diminished SGawEE at 8 weeks of age.

In a multivariate analysis prior wheeze and a family history of asthma were no longer significantly associated with SGawEE at 1 year (table 5). However, at 1 year sGaweE remained significantly diminished in those whose mothers reported smoking postnatally (95\% CI -0.71 to $-0.10 ; p=0.01$ ) and in those with 
Table 5 End expiratory specific conductance (sGawEE) at 1 year: associations with prior wheezing and other factors

\begin{tabular}{|c|c|c|c|}
\hline & $\begin{array}{l}\text { Difference in sGaweE } \\
(/ \mathrm{s} / \mathrm{kPa}) \text { at } 1 \text { year }\end{array}$ & $95 \%$ confidence interval & $p$ value \\
\hline \multicolumn{4}{|l|}{ Univariate analyses: } \\
\hline Prior physician diagnosed wheeze (baseline: no wheeze) & -0.45 & -0.76 to -0.14 & $<0.01$ \\
\hline Maternal smoking postnatally (baseline: no maternal smoking) & -0.54 & -0.81 to -0.27 & $<0.001$ \\
\hline Family history of asthma (baseline: no family history) & -0.31 & -0.62 to 0.00 & $<0.05$ \\
\hline sGawEE at 8 weeks of age (per unit $(/ \mathrm{s} / \mathrm{kPa})$ reduction) & -0.28 & -0.13 to -0.43 & $<0.001$ \\
\hline Sex (baseline: male) & 0.006 & -0.23 to 0.34 & 0.685 \\
\hline \multicolumn{4}{|l|}{ Multivariate analyses*: } \\
\hline Prior physician diagnosed wheeze (baseline: no wheeze) & -0.21 & -0.58 to 0.15 & 0.25 \\
\hline Maternal smoking postnatally (baseline: no maternal smoking) & -0.40 & -0.71 to -0.10 & 0.01 \\
\hline Family history of asthma (baseline: no family history) & -0.04 & -0.38 to 0.30 & 0.81 \\
\hline sGawEE at 8 weeks of age (per unit $(/ \mathrm{s} / \mathrm{kPa}$ ) reduction) & -0.20 & -0.36 to -0.03 & 0.018 \\
\hline
\end{tabular}

*Data calculated after allowing for those variables found to be significant in univariate analyses (prior wheeze, maternal smoking, family history of asthma, and sGaweE at 8 weeks of age).

diminished sGaweE at 8 weeks $(95 \%$ CI -0.36 to $-0.03 ; \mathrm{p}=0.018)$. A model incorporating only maternal smoking and sGawEe at 8 weeks accounted for $23 \%$ of the variation in sGawEE at 1 year $\left(r^{2}=0.228\right)$.

\section{Discussion}

The longitudinal data obtained over the first year of life in this cohort confirm that this is a period of considerable growth and development of the respiratory system with a twofold increase in FRCpleth, a halving of Raw, and a small reduction in sGaw but no change in sCrs. Respiratory rate and tPTEF:tE also declined significantly with increasing age, which may reflect continued alveolar and airway development as well as greater stability of end expiratory volume. ${ }^{9}$

We have found that maternal smoking and diminished airway function measured early in life are independently associated with lower levels of airway function at the end of the first year. Although sGaweE was lower at 1 year of age in infants with prior wheezing, our findings suggest that this association may be mediated by diminished premorbid airway function, reflecting impaired growth and development during fetal and very early life. Although a family history of asthma was not independently associated with impaired airway function at 1 year, this does not preclude an indirect effect of a genetic predisposition to asthma, possibly mediated through its association with diminished premorbid airway function. ${ }^{2}$

The infants included in the current study were representative of consecutive births in two general practices in inner London. ${ }^{2}$ The prevalence of smoking by mothers during pregnancy and postnatally is consistent with that reported from national samples in the $\mathrm{UK}^{20}$ and was biochemically validated. Physicians and parents were blinded to respiratory function results, as was the reviewer who ascertained physician diagnosed episodes from medical records, while those calculating respiratory function parameters were blinded to the wheezing and smoking exposure status of the infants.

The first year cumulative incidence of physician diagnosed wheezing is comparable to that reported previously from South London. ${ }^{21}$ Although higher than that reported from Tucson, ${ }^{1}$ this may reflect the higher prevalence of maternal smoking in this inner city population.
Cumulative incidence was higher in Perth, but was estimated from parental report rather than physician diagnosis of wheeze. ${ }^{3}$

Our findings are representative of the spectrum of wheezing presenting in primary care. In the current study almost half the infants experiencing a first wheezing episode sustained one or more subsequent episodes in the first year. However, the majority of episodes were managed in the community, with only four infants requiring hospital admission. In contrast, in the Tucson study all wheezing illnesses were managed in the community, and only one third $(n=8)$ of infants experienced further episodes. ${ }^{1}$ While there has been increasing interest in the relation of early infections to subsequent development of atopic illness, ${ }^{22}$ this was not a prior hypothesis of this study. Thus, prospective data on infections, including those of the upper respiratory tract, are not available.

In this study the primary measure of airway function was sGaw, a measure of airway function corrected for lung size. While the anatomical site of intrathoracic airway calibre cannot be located precisely with any of the currently available infant lung function tests, plethysmographic measures of Raw and sGaw are generally considered to reflect primarily the calibre of the central airways, ${ }^{23}$ whereas maximal flow at FRC ('்max FRC), as used in several previous epidemiological studies, ${ }^{1424}$ is thought to reflect more peripheral airway function. Although the latter is of value in detecting early influences on airway function in infants, resting lung volume, which was of specific interest in this study, cannot be assessed simultaneously.

Diminution of airway calibre may reflect several mechanisms including anatomical changes in lumen size, increased thickness or compliance of the airway wall, secretions, bronchoconstriction, or relative lack of distending pressure due to low elastic recoil. ${ }^{25}$ However, since infants in the current study were asymptomatic at testing with no evidence of hyperinflation or any difference in sCrs, the observed reduction in airway conductance at 1 year associated with maternal smoking or diminished premorbid airway function most likely reflects alterations in airway structure or calibre. Our findings are consistent with alterations in airway geometry in that diminished airway function shortly after birth is thought to reflect congenitally small airways and impaired 
fetal airway development. ${ }^{124}$ We did not find any sex differences in sGaw in the current study. In previous studies we have reported marked sex differences in VंmaxFRC when using the "squeeze" technique, ${ }^{16}{ }^{26}$ which suggests that sex differences may relate primarily to the size and function of the peripheral rather than central airways and reflect sex differences in respiratory development. ${ }^{27}$

While several population based longitudinal studies have examined lung function during early infancy in relation to subsequent respiratory symptoms and respiratory function in later childhood, few have assessed the growth and development of the respiratory system in later infancy by including repeat measures of infant lung function. ${ }^{328}$ Young et al observed reduced forced expiratory flow at 1 year in infants with parentally reported wheezing, but did not report the association with prior respiratory function. ${ }^{3}$ Tager et al observed diminished forced expiratory flow at 18 months of age in infants of mothers who smoked during pregnancy, but did not report the influence of prior wheezing or a family history of asthma. ${ }^{28}$

While tPTEF:tE is diminished in young infants who subsequently wheeze, ${ }^{12}$ our data do not support the converse association of diminished tPTEF:tE at 1 year in those with prior wheeze. We have previously shown that tPTEF:tE is only weakly related to measures of airway function in young infants aged over 13 weeks. ${ }^{13}$ The findings of the current study suggest that, in older infants without clinically significant airway disease, variation in the ratio of peak tidal expiratory flow to expiratory time does not reflect the mechanical properties of the lung or airway calibre.

We found maternal smoking to be a significant and independent predictor of diminished sGaw at 1 year, but cannot establish the relevant timing of exposure since women who smoked postnatally also smoked during pregnancy. However, in this cohort Raw was raised but sGaw was not diminished at 8 weeks of age in infants whose mothers smoked in pregnancy, ${ }^{2}$ suggesting that the effects of prenatal exposure to maternal smoking on lung development may initially be mediated by impaired fetal growth and micronutrient or other maternal nutritional deficiencies. ${ }^{29} 30$

Our findings add to the growing body of evidence supporting the association between maternal smoking and impaired respiratory function in offspring. ${ }^{28}{ }^{31}$ Elliot et al reported that inner airway wall thickness was increased in infants dying suddenly and unexpectedly at about 6 months of age and whose mothers smoked heavily during pregnancy and postnatally. ${ }^{32}$ They suggested that postnatal exposure to tobacco smoke represents a true inhalational insult to the airways, in contrast to in utero exposure which may have indirect effects on the respiratory system mediated by alterations in airway wall collagen thickness and neurological control of respiration. As most studies are unable to distinguish the temporal effects of maternal smoking, direct evidence for these hypotheses is lacking. However, the different patterns of airway abnormality observed at different ages in this and an earlier study ${ }^{16}$ suggest that this is biologically plausible. Thus, in utero exposure may be consistent with alterations in control of respiration and airway growth and development, and postnatal exposure with diminished airway calibre due to airway wall inflammation and oedema.

Information linking early measures of infant respiratory function to spirometric and other indices in later childhood and adult life are very limited..$^{33}$ In the Tucson Children's Respiratory Study, infants with transient early wheezing were more likely to have persistence of earlier impaired airway function to 6 years of age, despite being currently asymptomatic. ${ }^{7}$ Children with transient wheezing were also more likely to have a mother who smoked and to have non-reversible defects in forced expiratory volume in 1 second $\left(\mathrm{FEV}_{1}\right)$ by the age of $11 .^{34}$ In a subsequent report, reversible defects were reported by the age of 13 in those with respiratory syncytial virus associated lower respiratory illnesses in the first 3 years of life..$^{35}$ Upton et al reported diminished $\mathrm{FEV}_{1}$ in the adult offspring of mothers who smoked ${ }^{36}$ and suggested that maternal smoking may account for some of the unexplained variance in airway function in adult life. If this is the case, secular trends in smoking by young women and mothers ${ }^{20}$ suggest that this may be a risk factor of increasing public health importance. This is particularly so in the light of recent work demonstrating that diminished $\mathrm{FEV}_{1}$ is an important predictor of all-cause mortality in adult life. ${ }^{37}$ It is therefore increasingly relevant to examine whether there are adverse effects of potentially avoidable factors such as maternal smoking on the growth and development of the respiratory system.

One important question has been to determine whether children who experience lower respiratory illnesses in early life have preexisting abnormalities of airway function that manifest during viral infections, or whether the lower respiratory illness itself produces changes in the lower airways that predispose the infant to other problems. Our findings are consistent with the hypothesis that, at a population level, diminished premorbid airway function provides the link between wheezing lower respiratory illness and diminished airway function at 1 year. Maternal smoking remains an important and avoidable cause of impaired airway development and function in infancy.

We thank the parents and infants who took part; the general practitioners and health visitors of the Chrisp Street and St Stephen's Road Health Centres for their support and permission to contact families under their care; Liane Pilgrim who recruited and visited families, entered data and collated urine specimens for cotinine analysis; Colin Feyerabend at the Poisons Unit, New Cross Hospital for cotinine analyses; Debby Unit, New Cross Hospital for cotinine analyses; Debby MacNally for help with retrieving medical records; and Helena
Wagstaff for help with recruiting.

This research was supported by the Wellcome Trust, the National Asthma Campaign, the British Lung Foundation, the Dunhill Medical Trust, the Child Health Research Appeal Trust, SIMS Portex Ltd, and the Muirhead Trust. Research at Trust, SIMS Portex Ltd, and the Muirhead Trust. Research at
the Institute of Child Health and Great Ormond Street Hospithe for Children NHS Trust benefits from R\&D funding received from the NHS Executive. 
1 Martinez FD, Morgan WJ, Wright AL, et al. Diminished lung function as a predisposing factor for wheezing respira-

2 Dezateux C, Stocks J, Dundas I, et al. Impaired airway function and wheezing in infancy. The influence of maternal smoking and a genetic predisposition to asthma. Am $\mathscr{F}$ Respir Crit Care Med 1999;159:403-10

3 Young S, Arnott J, O'Keeffe PT, et al. The association between early life lung function and wheezing during the first 2 years of life. Eur Respir $\mathcal{F}$ 2000;15:151-7.

4 Dezateux C, Stocks J. Lung development and early origins of childhood respiratory illness. Br Med Bull 1997;53:4057.

5 Rona RJ, Gulliford MC, Chinn S. Effects of prematurity and intrauterine growth on respiratory health and lung function in childhood. BMF 1993;306:817-20.

6 Shaheen SO, Barker DJP. Early lung growth and chronic airflow obstruction. Thorax 1994;49:533-6.

7 Martinez FD, Wright AL, Taussig LM, et al. Asthma and wheezing in the first six years of life. $N$ Engl $f \mathrm{Med}$ wheezing in the

8 Leeder SR, Corkhill RT, Wysocki MJ, et al. Influence of personal and family factors on ventilatory function of children. Br F Prev Soc Med 1976;30:219-24.

9 Stocks J. Respiratory physiology during early life. Monald Arch Chest Dis 1999;54:358-64.

10 Stocks J, Sly PD, Tepper RS, et al. Infant respiratory function testing. New York: John Wiley, 1996.

11 Dundas I, Dezateux CA, Fletcher ME, et al. Comparison of single-breath and plethysmographic measurements of resistance in infancy. Am F Respir Crit Care Med 1995;151: 1451-8.

12 Stocks J, Dezateux CA, Jackson EA, et al. Analysis of tidal breathing parameters in infancy: how variable is $\mathrm{t}_{\mathrm{PTEF}}: \mathrm{t}_{\mathrm{E}}$ ? Am $\mathcal{F}$ Respir Crit Care Med 1994; 150:1347-54.

13 Dezateux CA, Stocks J, Dundas I, et al. The relationship between tPTEF:tE and specific airways conductance in infancy. Pediatr Pulmonol 1994;18:299-307.

14 Young S, Le Souëf PN, Geelhoed GC, et al. The influence of a family history of asthma and parental smoking on airway
responsiveness in early infancy. $N$ Engl 7 Med 1991;324: responsivenc $1168-73$

15 Stick SM, Burton PR, Gurrin L, et al. Effects of maternal smoking during pregnancy and a family history of asthma on respiratory function in newborn infants. Lance 1996;348:1060-4.

16 Hoo A-F, Henschen M, Dezateux C, et al. Respiratory function among preterm infants whose mothers smoked during pregnancy. Am ₹ Respir Crit Care Med 1998;158:700-5.

17 Freeman JV, Cole TJ, Chinn S, et al. Cross sectional stature and weight reference curves for the UK, 1990. Arch Dis Child 1995;73:17-24

18 Jarvis MJ, Tunstall-Pedoe H, Feyerabend C, et al. Comparison of tests used to distinguish smokers from nonsmokers. Am F Public Health 1987;77:1435-8.

19 Cohen J. Statistical power analysis for the behavioural sciences. Hillsdale, New Jersey: Erlbaum Associates, 1988.
20 Owen L, McNeill A, Callum C. Trends in smoking during pregnancy in England, 1992-7: quota sampling surveys. BMF 1998;317:728.

21 Watkins CJ, Burton P, Leeder S, et al. Doctor diagnosis and maternal recall of lower respiratory illness. Int $\mathcal{F}$ Epidemiol 1982;11:62-6.

22 Illi S, von Mutius E, Lau S, et al. Early childhood infectious diseases and the development of asthma up to school age: a birth cohort study. BMf 2001;322:390-5.

23 Macklem PT. The physiology of small airways. Am $\mathcal{f}$ Respir Crit Care Med 1998;157:S181-3.

24 Hanrahan JP, Tager IB, Segal MR, et al. The effect of maternal smoking during pregnancy on early infant lung function. Am Rev Respir Dis 1992:145:1129-35.

25 Stocks J. Developmental physiology and methodology. $A m \mathcal{F}$ Respir Crit Care Med 1995;151:S15-17.

26 Stocks J, Henschen M, Hoo A-F, et al. The influence of ethnicity and gender on airway function in preterm infants. Am ₹ Respir Crit Care Med 1997;156:1855-62.

27 Becklake MR, Kauffmann F. Gender differences in airway behaviour over the human life span. Thorax 1999;54:111938.

28 Tager IB, Ngo L, Hanrahan JP. Maternal smoking during pregnancy: effects on lung function during the first 18 months of life. Am F Respir Crit Care Med 1995;152:97783.

29 Margetts BM, Jackson AA. Interactions between people's diet and their smoking habits: the dietary and nutritional survey of British adults. BMF 1993;307:1381-4.

30 Godfrey K, Robinson S, Barker DJP, et al. Maternal nutrition in early and late pregnancy in relation to placental and fetal growth. BMF 1996;312:410-4.

31 Stein RT, Holberg CJ, Sherrill D, et al. Influence of parental smoking on respiratory symptoms during the first decade of life. Am ₹ Epidemiol 1999;149:1030-7.

32 Elliot J, Vullermin P, Robinson P. Maternal cigarette smoking is associated with increased inner airway wall thickness in children who die from sudden infant death syndrome. Am f Respir Crit Care Med 1998;158:802-6.

33 Britton J, Martinez FD. The relationship of childhood respiratory infection to growth and decline in lung function. $\mathrm{Am}$ 7 Respir Crit Care Med 1996;154:S240-5.

34 Stern DA, Morgan WJ, Taussig LM, et al. Lung function at age 11 in relation to early wheezing (abstract). Am $\mathcal{f}$ Respir Crit Care Med 1999;159:148.

35 Stein RT, Sherrill D, Morgan WJ, et al. Respiratory syncytial virus in early life and risk of wheeze and allergy by age 13 years. Lancet 1999;354:541-5.

36 Upton MN, Watt GCM, Davey-Smith G, et al. Permanent effects of maternal smoking on offspring's lung function. Lancet 1998;352:453.

37 Hole DJ, Watt GCM, Davey-Smith G, et al. Impaired lung function and mortality risk in men and women: findings from the Renfrew and Paisley prospective population study. BMF 1996;313:711-5. 